\title{
Absence of cardiovascular drift during prolonged arm-crank exercise in individuals with spinal cord injury
}

\author{
Masahiro Horiuchi ${ }^{1,2} \cdot$ Yoshiyuki Fukuoka $\mathbb{D D}^{3}$
}

Received: 21 January 2019 / Revised: 15 May 2019 / Accepted: 18 May 2019 / Published online: 4 June 2019

(c) International Spinal Cord Society 2019

\begin{abstract}
Study design: Observational study

Objective To investigate the effects of prolonged arm-crank exercise on cardiovascular drift $\left(\mathrm{CV}_{\mathrm{drift}}\right)$ in spinal cord injury (SCI).

Setting This is a community-based supervision study

Methods Ten participants with motor -complete or incomplete SCI (lesion level T7-L1), and 10 able-bodied (AB) participants matched for age performed a 40-min arm-crank exercise at an intensity of $50 \%$ of peak oxygen uptake $\left(\mathrm{VO}_{2}\right)$.

Results During the exercise, there were no significant differences between the groups in $\mathrm{VO}_{2}$, tissue $\mathrm{O}_{2}$ saturation in the biceps brachii (active muscle), and chest and arm skin temperature (all $P>0.05$ ). In the $\mathrm{AB}$, heart rate (HR) increased within the first $15 \mathrm{~min}$ of the exercise and continued to increase until the end of the exercise; however, in the SCI, HR increased within first $15 \mathrm{~min}$ of the exercise and then remained constant until the end of exercise. After 10 min of exercise, thigh skin temperature had increased more in the SCI than in the AB $(P<0.05)$. Thigh skin blood flow $(\mathrm{SkBF})$ continued to increase after $10 \mathrm{~min}$ of exercise in the AB but remained almost stable in the SCI. Relative changes in the thigh SkBF were associated with changes in HR during exercise between the values at $10 \mathrm{~min}$ and $40 \mathrm{~min}$ in the pooled data $\left(R^{2}=0.706, P<0.001\right)$. Conclusions $\mathrm{CV}_{\text {drift }}$ during the prolonged arm-crank exercise was not observed in individuals with SCI. This might be partially explained by different responses in cutaneous circulation within the inactive muscles of these participants.
\end{abstract}

\section{Introduction}

During prolonged, moderate-intensity exercise, the phenomenon of a rise in heart rate (HR) and a decrease in stroke volume (SV) in able-bodied (AB) individuals, so called cardiovascular drift $\left(\mathrm{CV}_{\text {drift }}\right)$ is well known $[1,2]$.

Supplementary information The online version of this article (https:// doi.org/10.1038/s41393-019-0301-5) contains supplementary material, which is available to authorized users.

Masahiro Horiuchi

mhoriuchi@mfri.pref.yamanashi.jp

1 Division of Human Environmental Science, Mt. Fuji Research Institute, Kami-yoshida 5597-1, Fuji-yoshida-city 4030005 Yamanashi, Japan

2 Northern Region Life Long Sports Center, Hokusho University, Bunkyoudai 23, Ebetsu-city 0698511 Hokkaido, Japan

3 Faculty of Sports Science, Doshisha University, Tatara 1-3, Kyotanabe-city 6100394 Kyoto, Japan
Traditionally, it has been thought that $\mathrm{CV}_{\text {drift }}$ is caused by a progressive increase in skin blood flow (SkBF) as body temperature rises [1-4]; to maintain core body temperature, blood flow is redistributed to the skin, increasing the skin's venous volume while reducing ventricular filling pressure and end-diastolic volume, thereby resulting in a decline in SV [1]. However, other research has questioned this relationship between increased SkBF and $\mathrm{CV}_{\text {drift }}[5,6]$. Notably, literature that has previously examined the potential mechanisms of $\mathrm{CV}_{\text {drift }}$ used larger muscle groups exercise (e.g., leg cycling) [2] and, thus, data on the phenomenon and mechanisms of $\mathrm{CV}_{\text {drift }}$ during smaller muscle groups exercise (e.g., arm-crank exercise) are limited.

For individuals with paralyzed lower limbs, e.g., spinal cord injury (SCI), upper-body exercise and periodic exercise training is important, and potentially reduces the risk of cardiovascular disease [7]. Their exercise necessarily involves smaller muscle groups (i.e., upper body muscles) as their lower limbs are paralyzed. This is especially the case for athletes with SCI participating in actual sports fields, such as wheelchair marathons or ball-games, which 
can involve prolonged exercise ( $>30 \mathrm{~min}$ ) [8]; thus a better understanding of $\mathrm{CV}_{\text {drift }}$ with prolonged exercise is of particular relevance in these athletes. It has been suggested that afferent input to the thermoregulatory center in the hypothalamus is reduced in individuals with SCI $[9,10]$, leading to attenuated vasomotor control and sweating responses below the level of the lesion [11-13]. Whether SkBF contributes to $\mathrm{CV}_{\text {drift }}$ has been debated, but, perhaps, a reduced sweat response (i.e., limited increase in SkBF) in individuals with SCI, may attenuate the reduction in plasma volume during exercise, thereby, suppressing $\mathrm{CV}_{\text {drift }}$ through maintaining SV [14].

However, only a few studies have examined $\mathrm{CV}_{\text {drift }}$ in individuals with SCI during prolonged exercise (defined as constant-rate exercise at moderate intensity $(50-75 \%$ of maximal oxygen uptake) that lasts at least $10 \mathrm{~min}$ and that would be sufficient to cause $\mathrm{CV}_{\text {drift }}[1]$ ), and these have shown equivocal results. Fitzgerald et al. reported that higher HR in individuals with SCI with lesions below thoracic (T) 6 could not compensate for the decreased SV to maintain cardiac output (CO) [15]. In contrast, it was reported that, during prolonged exercise, individuals with SCI with lesions below T6 maintained $\mathrm{CO}$ by an increase in HR; however, those with lesions above T6 cannot fully compensate for the SV reduction by an increase in HR, resulting in declines in $\mathrm{CO}$ [14]. In comparison, Zacharakis et al. [16] demonstrated that both individuals with SCI with lesions between $\mathrm{T} 4$ and $\mathrm{T} 6$, and $\mathrm{AB}$ individuals showed progressive increases in HR during a 60-min wheelchair exercise at $55 \%$ of their peak oxygen uptake $\left(\mathrm{VO}_{2 \text { peak }}\right)$ with no differences between the two groups in the increasing rate of HR. Surprisingly, they also found that SV and CO showed significantly lower values in individuals with SCI than in $A B$ individuals, suggesting that an increased $H R$ may not be required (or could not compensate) for maintaining CO in individuals with SCI [16]. From the wider literature, in addition to the lack of underlying mechanisms in $\mathrm{CV}_{\text {drift }}$ between individuals with $\mathrm{SCI}$ and $\mathrm{AB}$ individuals, differences in study design have made it difficult to match a consensus about $\mathrm{CV}_{\text {drift }}$ in individuals with SCI. For example, the studies included trained men $[14,16]$ and sedentary women [15], and were conducted in thermoneutral $\left(\sim 24^{\circ} \mathrm{C}\right)[15,16]$ and a hot environment $\left(\sim 35^{\circ} \mathrm{C}\right)$ [14]. Additionally, two has small sample size (with fewer than five in the individuals with SCI) $[14,15]$, the participants had different lesion level, and the studies involved different exercise times (45-90 $\mathrm{min}$ ) [14-16].

Generally, $\mathrm{CV}_{\text {drift }}$ may have an important role in maintaining $\mathrm{CO}$ to meet metabolic demand (oxygen uptake; $\mathrm{VO}_{2}$ ) during prolonged exercise. According to Fick's equation [17], $\mathrm{VO}_{2}$ is determined by the products of $\mathrm{CO}$ and arterial-venous $(a-v) \mathrm{O}_{2}$ differences (i.e., $\mathrm{O}_{2}$ utilization). Thus, continuous measurement of $\mathrm{O}_{2}$ utilization during upper-body exercise can provide further insight for factors that explain $\mathrm{CV}_{\text {drift }}$ in individuals with $\mathrm{SCI}$.

Accordingly, we hypothesized that $\mathrm{CV}_{\text {drift }}$ during prolonged arm-crank exercise in individuals with SCI is smaller compared with $\mathrm{AB}$ individuals because of a limited increase in SkBF in their paralyzed limbs. To test these hypotheses, we assessed SkBF in the lower limbs and muscle tissue $\mathrm{O}_{2}$ saturation $\left(\mathrm{StO}_{2}\right)$ in the upper limbs using near-infrared spectroscopy (NIRS) [18] and HR kinetics during prolonged arm-crank exercise.

\section{Methods}

\section{Participants}

Men with complete or incomplete participants with SCI ( $n$ $=10)$, and age-matched $\mathrm{AB}(n=10)$ participants voluntarily took part in this study. After a detailed explanation of the study procedures and possible risks, participants gave written informed consent. All procedures were approved by the ethical committee, and were performed in accordance with the Declaration of Helsinki (HOKUSO UNIV, 200902). The participants with SCI engaged in regular physical activity (basketball, tennis, and rugby with a wheelchair, 1-2 $\mathrm{h}$ per day, 3-5 days per week). AB participants also engaged in regular recreational sports with similar frequency. Both groups were recruited through an advertisement at Hokuso University. None of the participants took medication or were smokers. In addition, $A B$ volunteers were excluded from participation if they had a history of cardiovascular disease or upper arms orthopedic disease (e.g., fracture, muscle and tendon rupture) or a body mass index (BMI) $>25 \mathrm{~kg} / \mathrm{m}^{2}$. The physical characteristics of both groups are shown in Table 1 .

\section{Study protocols}

Exercise intensity and duration was chosen based on preliminary tests in our laboratory and on previous reports [14-16]. The participants were asked to abstain from caffeinated beverages for $12 \mathrm{~h}$ and from strenuous physical activity and alcohol for at least $24 \mathrm{~h}$ before the study. The participants were familiarized with all the measurement techniques, including the arm-crank exercise with face mask. All trials were conducted in a custom-made environmental chamber (Maeda Electrical Works Co, Ltd., Sapporo, Japan) maintained at a temperature of $25^{\circ} \mathrm{C}$ with a relative humidity of $40 \%$. To determine an individual's peak aerobic capacity, an incremental arm-crank exercise was performed using an arm-crank ergometer (Rehab Trainer 881E, Monark, Stockholm, Sweden). The exercise started with 4 min of unloaded arm-crank at $50 \mathrm{rpm}$., after 
Table 1 Characteristics of each spinal cord injury (SCI) group participant and mean values for the able bodied (AB) and SCI groups

\begin{tabular}{|c|c|c|c|c|c|c|c|c|}
\hline Participant & Injury level & Grade & $\begin{array}{l}\text { Injury duration } \\
\text { (years) }\end{array}$ & $\begin{array}{l}\text { Age } \\
\text { (years) }\end{array}$ & $\begin{array}{l}\text { Heigh- } \\
\text { t }(\mathrm{cm})\end{array}$ & $\begin{array}{l}\text { Body } \\
\text { weight }(\mathrm{kg})\end{array}$ & $\begin{array}{l}\text { Body mass } \\
\text { index }\left(\mathrm{kg} \mathrm{m}^{2}\right)\end{array}$ & $\begin{array}{l}\text { ATT } \\
(\mathrm{mm})\end{array}$ \\
\hline 1 & $\mathrm{~T} 7$ & A & 6 & 26 & 181 & 69.1 & 21.1 & 4.5 \\
\hline 2 & $\mathrm{~T} 7$ & A & 14 & 36 & 176 & 61.0 & 19.7 & 5.2 \\
\hline 3 & $\mathrm{~T} 7$ & A & 8 & 28 & 170 & 58.4 & 20.2 & 6.3 \\
\hline 4 & $\mathrm{~T} 8$ & A & 12 & 32 & 175 & 66.2 & 21.6 & 4.8 \\
\hline 5 & T9-10 & A & 9 & 32 & 167 & 63.4 & 22.7 & 5.1 \\
\hline 6 & T10-12 & A & 14 & 34 & 173 & 65.6 & 21.9 & 3.9 \\
\hline 7 & T11-12 & A & 4 & 24 & 168 & 59.5 & 21.1 & 4.5 \\
\hline 8 & L1 & A & 8 & 35 & 176 & 65.7 & 21.2 & 3.8 \\
\hline 9 & $\mathrm{~T} 12$ & B & 9 & 32 & 182 & 65.2 & 19.7 & 4.5 \\
\hline 10 & L1 & B & 15 & 41 & 166 & 51.3 & 18.6 & 3.1 \\
\hline SCI group & N.A. & N.A. & $10 \pm 4$ & $32 \pm 5$ & $173 \pm 6$ & $62.5 \pm 5.1$ & $20.8 \pm 1.2$ & $4.6 \pm 0.9$ \\
\hline $\mathrm{AB}$ group $(n=10)$ & N.A. & N.A. & N.A. & $31 \pm 5$ & $171 \pm 5$ & $62.2 \pm 7.7$ & $21.0 \pm 1.9$ & $5.1 \pm 0.8$ \\
\hline
\end{tabular}

Values in the final two lines are mean \pm standard deviation (SD). The participant's number from 1 to 10 is an individual characteristic of SCI. Grade indicates the injury classification according to the American Spinal Cord Injury Association Impairment Scale, as follows. A = Complete: No motor or sensory function is preserved. B = Incomplete: Sensory but not motor function is preserved below the neurological levels. $T$ thoracic, $L$ lumbosacral, ATT adipose tissue thickness, N.A. not appreciable

which the load was increased at a 10 watts $\cdot \mathrm{min}^{-1}$ increase at 50 rpm until exhaustion [7, 19]. The criteria for exhaustion were as follows: (1) failure to maintain 50 revolutions/min despite strong verbal encouragement, (2) a score of 19 on perceived exertion, and (3) respiratory gas exchange ratio $>1.1$. The test was terminated when the priority order from (1) to (2) and (3) was decided [7, 20]. One week following the incremental arm-crank exercise test, a 40-min prolonged arm-crank exercise was performed, with an intensity set at $50 \%$ of the $\mathrm{VO}_{2 \text { peak }}$ by the incremental arm-crank exercise test. In both exercises, participants with SCI moved to their wheelchair, and $\mathrm{AB}$ participants used a suitable wheelchair after 30 min rest in the supine position. Participants initially took a $10 \mathrm{~min}$ rest in a wheelchair and performed the exercises in an upright sitting position. The wheelchair was firmly fixed, and the participant's legs and feet were held in place with a strap. The pedal axis was aligned with the participant's shoulder, and the elbows were positioned in a slight flexion position [7]. To avoid autonomic dysreflexia, each individual with SCI were asked to empty their bladder before each arm-crank exercise. We confirmed that none of these participants experienced spasm in their lower limbs or symptoms of autonomic dysreflexia, such as severe headache, nausea, and bradycardia.

\section{Measurements}

Physical characteristics Height and body weight were measured, wearing only underwear after voiding the bladder. For all participants, height was measured using a nonelastic tape measure while lying in a $30^{\circ}$ supine position, as this approximated the method used to measure standing $\mathrm{AB}$ participants [21]. For individuals with SCI, body weight was measured using a custom scale with an individual's wheelchair. For AB participants, body weight was measured using a commercial body weight scale (TBF-410; TANITA, Tokyo, Japan). Adipose tissue thickness (ATT) at the biceps brachii was measured for all the participants by using B-mode ultrasound (NEMIO SSA550A; Toshiba, Tokyo, Japan).

\section{Metabolic and cardiac variables}

Metabolic variable of $\mathrm{VO}_{2}$ were measured at rest and during exercise by an online computerized breath-by-breath method (Vmax-C29; Nihon Koden, Tokyo, Japan). HR was continuously monitored by an electrocardiogram attached to a metabolic measuring system (Box Assy 2 Channel ECS; VIASYS Healthcare, Inc., PA, USA).

\section{Near-infrared spectroscopy variables}

Local tissue oxygenation profiles of the biceps brachii were measured using NIRS (BOM-L1TRW; Omegawave, Tokyo, Japan) [22]. This instrument uses three laser diodes (with wavelength of 780,810 , and $830 \mathrm{~nm}$ ) and calculates the relative tissue levels of oxygenated $\left(\mathrm{HbO}_{2}\right)$ and deoxygenated $(\mathrm{HHb})$ hemoglobin according to the modified Beer-Lambert law. The tissue $\mathrm{O}_{2}$ saturation of skeletal muscle $\left(\mathrm{StO}_{2}\right)$ was calculated as $\left[\mathrm{HbO}_{2} /\left(\mathrm{HbO}_{2}+\mathrm{HHb}\right) \times\right.$ $100 \%]$. NIRS optodes were placed over the belly of the biceps brachii on each participant's upper left arm [23]. The probe holder contained one light source probe, and two detectors were placed $1.5 \mathrm{~cm}$ (detector 1 ) and $3 \mathrm{~cm}$ (detector 
2) away from the source. The hemoglobin concentrations received by detector 1 were subtracted from those received by detector 2 . This procedure minimized the influence of SkBF [24]. NIRS signals can reach half the depth of the distance between the probe and detector [25], so in this study, the NIRS signals traversed at a depth between $\sim 7.5$ and $15 \mathrm{~mm}$. The NIRS signals were measured at $1-\mathrm{s}$ intervals throughout the experiment. It should be noted that the arterial cuff occlusion technique was not performed. This technique has been used to correct for differences in ATT [26]; however, in this study, the ATT of the biceps brachii in the two groups were similar. A further reason for not using this technique was that, during the preliminary test in our laboratory, some of the participants reported experiencing severe nausea and pain, probably, due to a result of wearing the cuff on fatigued muscles immediately after exercise.

\section{Cutaneous circulation variables}

Skin temperature was measured using a commercial thermistor (LT-8; Gram Co. Ltd., Saitama, Japan) at three locations: on the left chest (T-chest), the left upper arm (Tarm), and the left thigh (T-thigh). The data were collected at 1-s intervals throughout the study. SkBF at the left thigh was recorded using the laser Doppler method (Omega Flow FLO-N1; Omegawave, Tokyo, Japan) via a commercial AD converter (MacLab/8 s; AD Instruments, Sydney, Australia) with a sampling rate of $10 \mathrm{~Hz}$ and transferred to a laptop computer. The electrodes for skin temperature and SkBF were placed over the skin, and the electrodes for the T-arm and T-thigh were placed about $2 \mathrm{~cm}$ away from the NIRS or SkBF probe (Supplemental Fig. 1). The averages for each 30 -s interval were used in the analysis. Changes in these parameters from resting values were also calculated.

\section{Data analysis}

All physiological data $\left(\mathrm{VO}_{2}, \mathrm{HR}, \mathrm{StO}_{2}\right.$, and cutaneous circulation variables) were averaged every $20 \mathrm{~s}$ to represent overall kinetics during exercise. They were also averaged over $1 \mathrm{~min}$ intervals once every $5 \mathrm{~min}$ (i.e., at $4-5 \mathrm{~min}$, 9-10 $\mathrm{min}, 14-15 \mathrm{~min}$, followed by until $39-40 \mathrm{~min}$ ) for further statistical analysis. To compare SkBF between the groups, changes in SkBF were quantified as percentages of the resting baseline values and differences were shown as relative changes [27]. The $\mathrm{StO}_{2}$ and skin temperature variables were also quantified as changes from the resting baseline values.

\section{Statistical analysis}

All the data are presented as mean $\pm \mathrm{SD}$. Unpaired $t$ tests were used to compare physical characteristics and the resting physiological variables between the groups. A twoway repeated ANOVA (TimexGroups) was made to compare all physiological variables. The relationship between participant's $\mathrm{VO}_{2 \text { peak }}$ values and the relative changes in the HR between 10 and 40 min was approximated by a linear regression analysis. The relationship between the relative changes in the SkBF (values at 40 and $10 \mathrm{~min}$ ) and in the $\mathrm{HR}$ (values at 40 and $10 \mathrm{~min}$ ) was approximated by a quadratic function curve. A $P$ value less than 0.05 was considered statistically significant, and statistical analyses were performed using commercially available software packages (Sigma Stat 3.5; Hulinks, Chicago, IL).

\section{Results}

There were no significant differences in age, height, body weight, BMI, or ATT at the biceps brachii between the AB participants and individuals with SCI (Table 1).

\section{Resting metabolic and cardiovascular variables}

There were no significant differences in $\mathrm{VO}_{2}, \mathrm{HR}, \mathrm{StO}_{2}, \mathrm{~T}$ chest or T-arm (all $P>0.05$, Table 2). However, the baseline SkBF and T-thigh values in the individuals with SCI were significantly lower in the $\mathrm{AB}(P<0.05$, Table 2$)$.

\section{Cardiorespiratory and tissue $\mathrm{O}_{2}$ saturation during exercise}

Figure 1 shows the time course of the $\mathrm{VO}_{2}, \mathrm{HR}$, and $\mathrm{StO}_{2}$ in the two groups. The $\mathrm{VO}_{2}$ increased exponentially within the first $5 \mathrm{~min}$ of exercise and nearly constant by the end of the exercise in both groups (Fig. 1a). There were no significant

Table 2 Resting metabolic and cardiovascular variables between two groups

\begin{tabular}{|c|c|c|c|c|}
\hline & $\mathrm{AB}$ & SCI & $t$ & $P$ value \\
\hline $\mathrm{VO}_{2}, \mathrm{ml} \mathrm{min}-1$ & $308 \pm 33$ & $312 \pm 41$ & -0.242 & 0.819 \\
\hline HR, bpm & $69 \pm 8$ & $68 \pm 7$ & 0.313 & 0.758 \\
\hline $\mathrm{StO}_{2}, \%$ & $52.9 \pm 5.0$ & $57.4 \pm 5.9$ & -1.838 & 0.083 \\
\hline $\mathrm{T}$-chest, ${ }^{\circ} \mathrm{C}$ & $35.38 \pm 0.56$ & $35.42 \pm 0.71$ & -0.125 & 0.902 \\
\hline $\mathrm{T}$-arm, ${ }^{\circ} \mathrm{C}$ & $34.29 \pm 0.55$ & $34.16 \pm 0.71$ & 0.430 & 0.672 \\
\hline T-thigh, ${ }^{\circ} \mathrm{C}$ & $34.66 \pm 0.62$ & $33.21 \pm 0.64^{\mathrm{a}}$ & 5.177 & $<0.001$ \\
\hline $\mathrm{SkBF}, \mathrm{mV}$ & $6.07 \pm 2.18$ & $3.67 \pm 1.70^{\mathrm{a}}$ & 2.752 & 0.013 \\
\hline
\end{tabular}

Values are mean $\pm \mathrm{SD}$

$V \mathrm{O}_{2}$ pulmonary oxygen uptake, $H R$ heart rate; $b p m$ beats per minute, $\mathrm{StO}_{2}$ muscle oxygen saturation, $\mathrm{T}$ skin temperature, measured at the chest, arm, and thigh, $S k B F$ skin blood flow

aindicates significant differences between the AB and SCI groups. Note that $\mathrm{StO}_{2}$ was measured at the biceps brachii, and $\mathrm{SkBF}$ was measured at the vastus lateralis 

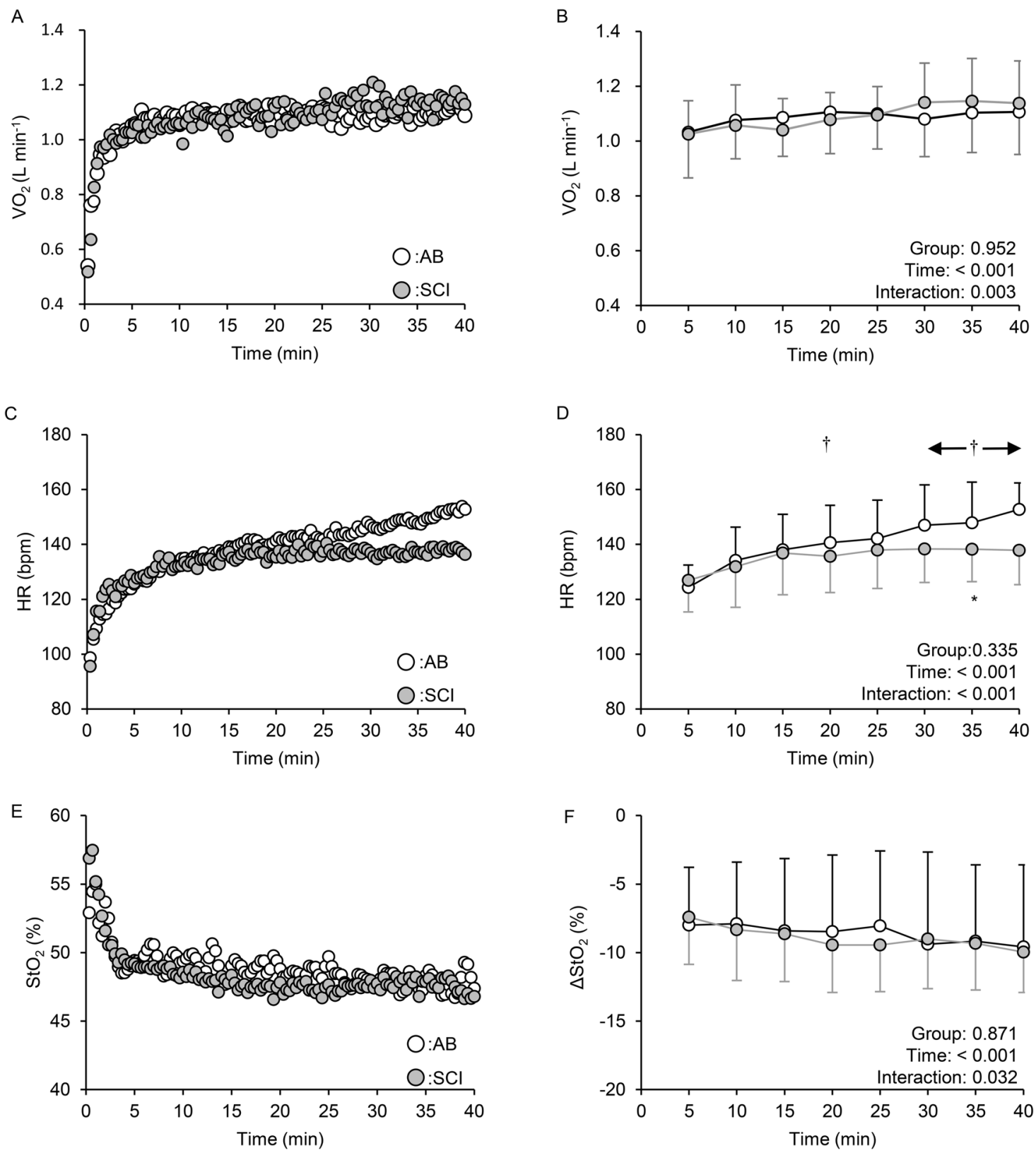

Fig. 1 Time courses of pulmonary oxygen uptake $\left(\mathrm{VO}_{2} ; \mathbf{a}, \mathbf{b}\right)$, heart rate (HR; panels c and d), and tissue $\mathrm{O}_{2}$ saturation $\left(\mathrm{StO}_{2} ; \mathbf{e}, \mathbf{f}\right)$ during 40-min prolonged exercise between the able-bodied (AB) and spinal cord injury (SCI) groups. The left-hand panels show mean values of averages over 20 -s intervals. The right-hand panels show the mean and

standard deviation (SD) values of averages over 5-min intervals. The white and gray circles indicate the $\mathrm{AB}$ and $\mathrm{SCI}$ groups, respectively. ${ }^{*} P<0.05$ between the $\mathrm{AB}$ and $\mathrm{SCI}$ groups at the same time point. $\dagger P<0.05$ vs. HR values at 15 min in the $\mathrm{AB}$ group

differences in $\mathrm{VO}_{2}$ between the groups at any of the 5-min time points (Fig. 1b, all $P>0.05$ ). The HR increased exponentially within the first $5-10 \mathrm{~min}$ of exercise in both groups. Thereafter, the $\mathrm{HR}$ of the $\mathrm{AB}$ group continued to increase until the end of the exercise; however, in the individuals with SCI, HR increased within the first $15 \mathrm{~min}$ of the exercise and then remained constant until the end of exercise (Fig. 1c). In the AB group, HR at 20, 30, 35, and $40 \mathrm{~min}$ of exercise was significantly higher than at $15 \mathrm{~min}$

$(P<0.05$, respectively); in contrast, there were no significant increases in HR after $15 \mathrm{~min}$ of exercise in the individuals with SCI (Fig. 1d). Moreover, HR at $40 \mathrm{~min}$ of prolonged exercise was significantly lower in the individuals with $\mathrm{SCI}$ compared with the $\mathrm{AB}$ group (Fig. 1d, $P=$ 0.008). The $\mathrm{StO}_{2}$ in both groups acutely decreased at the onset of exercise and decreased almost linearly up to around 5 min (approx. $-7 \%$ ). Thereafter, it continued to decrease slightly until the end of the exercise (approx. $-10 \%$ ) 
(Fig. 1e). Consequently, there were no significant differences in the changes of $\mathrm{StO}_{2}$ at any time points between the two groups (all $P>0.05$, Fig. 1f). There was no significant relationship between individual $\mathrm{VO}_{2 \text { peak }}$ and $\mathrm{CV}_{\text {drift }}$ values when data from both groups were pooled $(r=0.350$, $P=0.130, n=20)$.

\section{Cutaneous circulation kinetics during exercise}

Figure 2 shows the time courses of skin temperature at each site and SkBF in both as 20-s averages (Fig. 2a, c, e, g) and as relative changes from baseline in 5 min averages (Fig. 2b, $\mathrm{d}, \mathrm{f}, \mathrm{h})$. The kinetics of skin temperature at the chest and arm were similar between the $\mathrm{AB}$ participants and individuals with SCI (Fig. 2a, c). In both the T-chest and T-arm, a significant main effect of time was observed. T-chest and T-arm increased significantly until $20 \mathrm{~min}$ and $25 \mathrm{~min}$, respectively $(P<0.05)$; thereafter, they remained approximately constant until the end of exercise (Fig. 2b, d). The absolute values of $\mathrm{T}$-thigh in the $\mathrm{AB}$ participants were higher than in the individuals with SCI group until the midpoint of exercise; thereafter the values were similar (Fig. 2e). The increase in T-thigh from baseline was greater in the individuals with SCI than in the AB group (Fig. 2f). The SkBF at the thigh in the AB group showed an upward sigmoid curve but remained approximately constant in the individuals with SCI (Fig. $2 \mathrm{~g}$ ). There were significant differences in the changes in SkBF between the AB participants and individuals with SCI after $15 \mathrm{~min}$ of exercise (all $P<0.05$ ). The $\mathrm{SkBF}$ in the $\mathrm{AB}$ group appeared to continuously increase after $10 \mathrm{~min}$ of prolonged exercise (all $P<0.05$ vs. $10 \mathrm{~min}$ ) (Fig. 2h). When data from both groups were pooled, there was a significant relationship between changes in $\mathrm{HR}$ and the relative changes in SkBF between $10 \mathrm{~min}$ and $40 \mathrm{~min}$, (Fig. $3 ; R^{2}=0.706, P<0.001$ )

\section{Discussion}

The major findings of this study are as follows. First, the $\mathrm{VO}_{2}, \mathrm{StO}_{2}, \mathrm{~T}$-chest, and T-arm kinetics were similar between the groups throughout the $40 \mathrm{~min}$ of exercise. Second, after $15 \mathrm{~min}$, in $\mathrm{AB}$ individuals, HR continued to increase until the end of the exercise in the AB group, whereas it remained at almost constant value in the individuals with SCI. Third, SkBF at the thigh in AB group continued to increase from $10 \mathrm{~min}$ until the end of the exercise, but it remained approximately constant throughout in the individuals with SCI. Finally, greater increases in SkBF were associated with $\mathrm{CV}_{\text {drift }}$.

In this study, $\mathrm{CV}_{\text {drift }}$ occurred only in $\mathrm{AB}$ individuals, while HR stabilized after $\sim 10$ min of exercise in individuals with SCI. We also found no differences in the $\mathrm{VO}_{2}$ and the
$\begin{array}{lllll}\mathrm{StO}_{2} & \text { as an indirect indicator of } a-v & \mathrm{O}_{2} \text { differences [18] }\end{array}$ between both groups. Given Fick's equation, higher HR in $\mathrm{AB}$ participants may be the result of compensation for reductions in $\mathrm{SV}$ to maintain $\mathrm{CO}$. However, we must acknowledge this hypothesis is speculative and further studies are warranted. It has been suggested that the most probable explanation for a reduce in $\mathrm{VO}_{2 \max }$ is a decrease in maximal SV[2], so another hypothesis that lower $\mathrm{VO}_{2 \text { peak }}$ is associated with greater $\mathrm{CV}_{\text {drift }}$ may be reasonable [28, 29]. However, in the present study, we found no relationship between the individual $\mathrm{VO}_{2 \text { peak }}$ values and the magnitude of $\mathrm{CV}_{\text {drift }}$. It should be noted that the previous studies have conducted leg cycling for $\mathrm{AB}$ participants [28, 29]. In contrast, another study demonstrated that $\mathrm{VO}_{2 \text { peak }}$ in individuals with SCI (T7-L1) significantly increased after 30days of arm-crank exercise training for the $30 \mathrm{~min}$ per day, 3 days per week at an intensity of $50 \% \mathrm{HR}$ reserve [20]. That study also found that $\mathrm{VO}_{2}$ during sub -maximal constant-load arm-crank exercise (at $50 \% \mathrm{HR}$ reserve for $5 \mathrm{~min}$ ) remained unchanged throughout the 30-day training period, and that HR significantly decreased only after 7 days of training. These results suggest that an improvement of $\mathrm{VO}_{2 \text { peak }}$ may not affect $\mathrm{HR}$ during sub-maximal arm crank exercise [20]. Difficulties in determining true $\mathrm{VO}_{\text {2peak }}$ during an arm -crank exercise may also be considered. A recent study reported that, for participants with $\mathrm{SCIs}, \mathrm{VO}_{2 \text { peak }}$ values measured in an incremental arm-crank exercise were similar to those measured in a following verification test at $105 \%$ of peak power output [30]. However, in $\mathrm{AB}$ participants, $\mathrm{VO}_{2 \text { peak }}$ measured in the verification test was about $10 \%$ higher than that measured in the incremental text, suggesting that a subsequent verification test may be essential when measuring $\mathrm{VO}_{2 \text { peak }}$ of $\mathrm{AB}$ participants [30]. In the present study, we did not perform a verification test for either group, so this potential confounding factor may have affected the true $\mathrm{VO}_{2 \text { peak }}$ values, especially for the $\mathrm{AB}$ participants, as well as $\mathrm{CV}_{\text {drift }}$ and the relationship between $\mathrm{VO}_{2 \text { peak }}$ and $\mathrm{CV}_{\text {drift }}$.

Cutaneous circulatory responses could account for greater $\mathrm{CV}_{\text {drift }}$ in $\mathrm{AB}$ individuals. In the present study, there were no differences in the $\mathrm{T}$-chest and $\mathrm{T}$-arm between the two groups. The SCI lesions of the participants were below T8, so it is reasonable that the cutaneous responses at the chest and arm (s) were be similar between the groups. Therefore, upper-body cutaneous circulatory responses cannot explain the different HR responses between the groups. However, T-thigh and SkBF in the lower limb differed markedly between the groups. As sympathetic control of arteries and sweat glands in the lower body (T6-L2) projects from the T6-L2 segments, sympathetic pathways were not preserved in participants with SCI and lesions at T6-L2 [31]. Therefore, sympathetic adjustment for skin vascular responses acted less on SkBF in the lower limbs during the arm-crank 

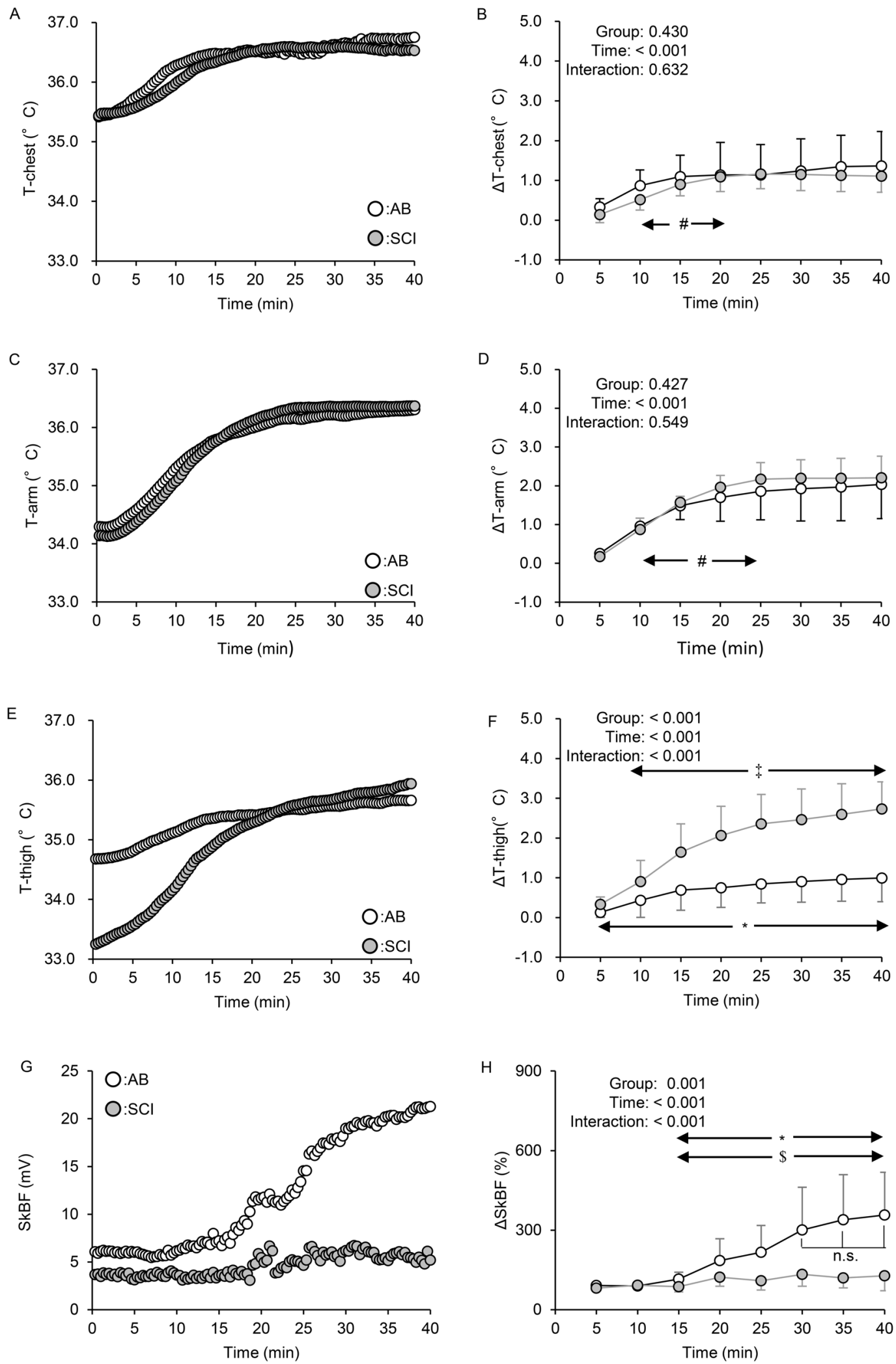

Fig. 2 Time courses of skin temperature at the chest (T-chest; $\mathbf{a}, \mathbf{b})$, arm (T-arm; $\mathbf{c}, \mathbf{d})$, thigh (T-thigh; $\mathbf{e}, \mathbf{f})$, and of thigh skin blood flow (SkBF; g, h) during 40-min prolonged exercise between the AB and SCI groups. The time bins and symbols are the same as in Fig. $1 . * P<0.05$ between the $\mathrm{AB}$ and $\mathrm{SCI}$ groups within the same time point. $\ddagger P<0.05$ vs. relative changes in T-thigh at $5 \mathrm{~min}$ in the SCI group. $\$ P<0.05$ vs. the changes in $\mathrm{SkBF}$ at $10 \mathrm{~min}$ from baseline in the $\mathrm{AB}$ group. $\# P<0.05$ vs. the previous value for T-chest or $\mathrm{T}$-arm when data for the two groups are pooled. $\mathrm{n} . \mathrm{s}$., non-significant 


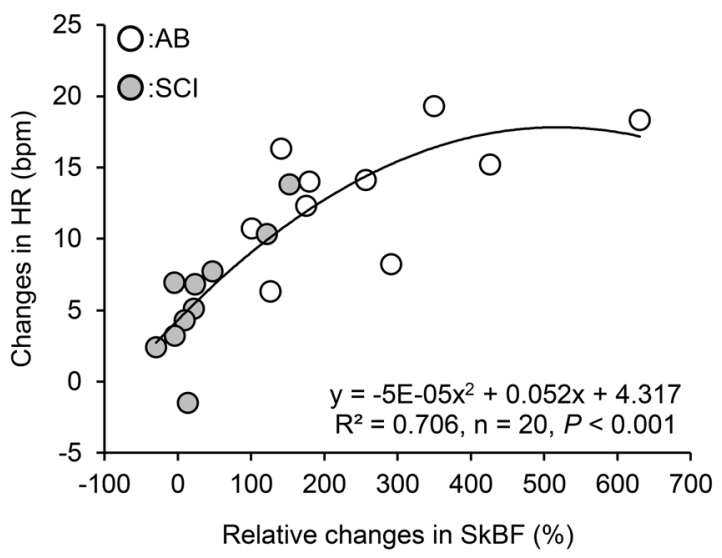

Fig. 3 Relationship between relative changes in thigh $\mathrm{SkBF}$ and changes in HR during prolonged exercise when data from the $\mathrm{AB}$ and SCI groups are pooled. Changes in SkBF and HR were calculated as the differences between $10 \mathrm{~min}$ and $40 \mathrm{~min}$ of exercise. Symbols are the same as in Fig. 1

exercise, which supported the idea that skin sympathetic responses were absent below the lesion, at any neurological level, in individuals with complete SCI [32].In addition, the greater increase in T-thigh in participants with SCI may indicate inefficient heat dissipation in the paralyzed limbs because lower changes in SkBF do not produce sufficient vasodilation. A previous study found that $\mathrm{SkBF}$ in the anterior thigh remained unchanged during a 30-min arm exercise in individuals with SCI with lesions between T6 and T12, while it increased in individuals with SCI lesions below T12, suggesting that injury levels may affect SkBF in paralyzed lower limbs [33]. Since most of the present study's individuals with SCI have lesions above T12, our results can be supported by the previous study [33].

Traditionally, $\mathrm{CV}_{\text {drift }}$ has been thought to be caused by a progressive increase in SkBF as body temperature rises [14]. The rise in SkBF suggests an increase in skin blood volume, leading to a reduction in end-diastolic volume and a decline in SV [1]. Indeed, it has been demonstrated that $\mathrm{HR}$ and SkBF increased, while SV decreased during $70 \mathrm{~min}$ of leg cycling [34]. Moreover, a previous study demonstrated that increases in HR were suppressed when the decline in SV was inhibited by suppressing the increase in SkBF with a cooling fan during 45-min submaximal exercise [35]. Therefore, our results may be supported by these previous studies $[34,35]$. In contrast, Coyle and colleague (s) used a partial $\beta$-adrenoreceptor blockade to manipulate $\mathrm{HR}$ and demonstrated that reductions in SV are associated with increases in HR and are not affected by SkBF [5, 6]. A notable issue may be that $\mathrm{SkBF}$ may directly affect $\mathrm{CV}_{\text {drift }}$ due to the experimental manipulating of SkBF in these previous studies $[5,6,35]$. Therefore, it may be difficult to determine a single robust factor accounting for $\mathrm{CV}_{\text {drift }}$, due to the broad range of circumstances.
A significant relationship between $\mathrm{HR}$ and SkBF obtained by the quadratic function curve indicates that HR changes increased exponentially in accordance with an increase in the SkBF until approx. 400\% (Fig. 3). Nose et al. reported that cutaneous blood flow increases during the first $20-30 \mathrm{~min}$ of exercise and remains fairly stable thereafter [36, 37]. In contrast, SV continuously declines during prolonged exercise, even after $30 \mathrm{~min}$ [38]. Given these previous study results, it could be speculated that $\mathrm{CV}_{\text {drift }}$ may be affected by SkBF from the initial period of exercise up to about $30 \mathrm{~min}$, whereas other influencing factors should be considered after $30 \mathrm{~min}$ of exercise. Indeed, the SkBF did not increase further after $30 \mathrm{~min}$ of exercise in $\mathrm{AB}$ individuals despite continuous increases in HR.

An important finding was the absence of $\mathrm{CV}_{\text {drift }}$ in the individuals with SCI during the prolonged arm-crank exercise. Higher HRs in individuals with SCI with lesion levels T6-T12 individuals has been frequently observed during submaximal $[14,39]$ and high-intensity exercise [40]. These responses have been considered a compensation for reductions in the SV to maintain CO. It is plausible that, after SCI, people's paralyzed lower limbs are immobilized, leading to complications, such as a decreased venous return, which is likely due to reduced muscle volume in the muscle pump [41, 42]. However, chronic immobilization also causes vascular changes, such as smaller diameter in the femoral artery [41, 43, 44] and decreased blood flow $[45,46]$, in which case, a small percentage of $\mathrm{CO}$ should be distributed to the lower limbs during arm-crank exercise.

\section{Study limitations}

There are numerous issues that limit the interpretation of these results, primarily the fairly homogenous, lower-level injury characteristics of the participants. Researchers have cautioned that neither body weight nor BMI account for differences between fat mass and fat- free mass between $\mathrm{AB}$ participants and individuals with SCI. After SCI, the individual's body composition undergoes various changes, such as reductions in muscle volume and accumulations of adipose tissue [47]. We did not assess body composition precisely using dual-energy X-ray absorptiometry, and we acknowledge that $\mathrm{CV}_{\text {drift }}$ may have been influenced by potential differences in fat mass and/or fat-free mass. Second, we could not measure body core temperature, because our ethical committee did not allow us the use of insertion type loggers including for measurement of rectal, esophageal, and oral telemetry pills and the measurement of SV using echo Doppler would have been technically difficult because of the large upper-body movement resulting from instability during single arm-crank exercise. In addition, we did not conduct experimental manipulations to change HR 
and/or SkBF, such as using sympathetic nerve blockades. For these reasons, we were not able to further clarify the detailed mechanisms underlying out findings on $\mathrm{CV}_{\text {drift. }}$ An assessment of these potential parameters to elucidate these underlying the mechanisms is needed in the near future.

\section{Perspectives}

In general, although the majority of individuals with SCI are inherently inactive, our results may indicate that people with SCI who regularly engage in wheelchair sports, such as basketball or rugby (1-2 $\mathrm{h}$ per day and 3-5 days per week), can perform a prolonged upper-body exercise with little physical strain (i.e., less $\mathrm{CV}_{\text {drift }}$ ). Periodic endurance upper-body exercise training has been recommended for reducing the risk of cardiovascular disease [7, 48-51]; it is, therefore, advisable that the majority of people with SCI should adhere to a regime of periodic upper-body endurance training. A recent study demonstrated that 10 weeks of armcrank training at an intensity of $70 \% \mathrm{VO}_{2 \text { peak }}$ significantly improved peak aerobic capacity and metabolic profiles in people with SCI [52]. Moreover, it was also reported that moderate-intensity upper-body exercise at $60-65 \% \mathrm{VO}_{2 \text { peak }}$ significantly improved $\mathrm{VO}_{2 \text { peak }}$ and fasting insulin concentration in people with SCI compared to the control group [53]. Taken together, a regime of periodic, upper-body endurance training with moderate-intensity exercise (i.e., $60-70 \% \mathrm{VO}_{2 \text { peak }}$ ) induced positive changes in aerobic and metabolic capacities in people with SCI.

Nightingale et al. [53] reviewed exercise guidelines for high-intensity interval training to promote vigorousintensity exercise and prevent cardiovascular diseases in people with SCI [54]. They postulated that vigorousintensity exercise may offer superior and more timeefficient stimulus for metabolic adaptations than moderateintensity exercise in this population [54]. Investigating high-intensity interval training on $\mathrm{CV}_{\text {drift }}$ would be challenging. However, care should be taken to avoid the possible risk of hyperthermia in individuals with SCI because of the lower amount of change in SkBF and the greater increase in the T-thigh in the paralyzed limbs of these individuals.

When we consider $>50 \%$ of injuries are in the cervical spinal segments, $\mathrm{CV}_{\text {drift }}$ in these participants might appear less because they lack cardiac sympathetic innervation, and their hearts will only be innervated by vagus nerve activation. Consequently, the increased HR during exercise may depend mainly on vagal withdrawal; this supports the values of $\mathrm{HR}_{\text {peak }}$ and $\mathrm{VO}_{2 \text { peak }}$, which were averaged to be approximately $110-120 \mathrm{bpm}$ and $8-12 \mathrm{ml} / \mathrm{kg} / \mathrm{min}$, respectively $[55,56]$. Thus, we believe that the lack of $\mathrm{CV}_{\text {drift }}$ in people with SCI with lesions at T6-L1 applies to the wider populations with SCI.

\section{Conclusion}

$\mathrm{CV}_{\text {drift }}$ was not observed in trained people with SCI during prolonged arm-crank exercise at an intensity of $50 \%$ of $\mathrm{VO}_{2 \text { peak }}$, while it continued to increase until the end of the exercise in $\mathrm{AB}$ individuals. The $\mathrm{VO}_{2}, \mathrm{StO}_{2}, \mathrm{~T}$-chest, and Tarm kinetics were similar between the groups. The SkBF at the thigh was significantly higher in $\mathrm{AB}$ participants than in individuals with SCI. When results of both groups were pooled, the relative changes in SkBF were associated with changes in $\mathrm{HR}$ during exercise, suggesting that $\mathrm{CV}_{\text {drift }}$ may be related to increased SkBF in inactive muscles.

\section{Data archiving}

The data sets generated and/or analyzed during the current study are available from the corresponding author on reasonable request.

Acknowledgements The authors thank all participants who took their time and effort.

Funding This study was partly supported by Japan Society for the Promotion of Science (No. 16700497)

Author contributions $\mathrm{MH}$ conceived and designed the current study. MH performed the experiment. MH and YF analyzed the data and interpreted the results. MH prepared figures and tables. MH drafted the first manuscript. MH and YF edited the manuscript and all authors approved the final version.

\section{Compliance with ethical standards}

Statement of Ethics The current study was approved by the ethical committee of Hokusho University. We certify that all applicable institutional regulations concerning the ethical use of human volunteers were followed during the course of this research.

Conflict of interest The authors declare that they have no conflict of interest.

Publisher's note: Springer Nature remains neutral with regard to jurisdictional claims in published maps and institutional affiliations.

\section{References}

1. Rowell LB. Human circulation. regulation during physical stress. New York: Oxford University Press, 1986, pp. 363-406.

2. Wingo JE, Ganio MS, Cureton KJ. Cardiovascular drift during heat stress: implications for exercise prescription. Exerc Sport Sci Rev. 2012;40:88-94.

3. Rowell LB. Human cardiovascular adjustments to exercise and thermal stress. Physiol Rev. 1974;54:75-159.

4. Rowell LB, Murray JA, Brengelmann GL, Kraning KK 2nd. Human cardiovascular adjustments to rapid changes in skin temperature during exercise. Circ Res. 1969;24:711-24.

5. Trinity JD, Pahnke MD, Lee JF, Coyle EF. Interaction of hyperthermia and heart rate on stroke volume during prolonged exercise. J Appl Physiol (1985). 2010;109:745-51. 
6. Fritzsche RG, Switzer TW, Hodgkinson BJ, Coyle EF. Stroke volume decline during prolonged exercise is influenced by the increase in heart rate. J Appl Physiol. 1999;86:799-805.

7. Horiuchi M, Okita K. Arm-cranking exercise training reduces plasminogen activator inhibitor 1 in people with spinal cord injury. Arch Phys Med Rehab. 2017;98:2174-80.

8. Veltmeijer MT, Pluim B, Thijssen DH, Hopman MT, Eijsvogels TM. Thermoregulatory responses in wheelchair tennis players: a pilot study. Spinal Cord. 2014;52:373-7.

9. Tam HS, Darling RC, Cheh HY, Downey JA. Sweating response: a means of evaluating the set-point theory during exercise. J Appl Physiol: Res Environ Exerc Physiol. 1978;45:451-8.

10. Boot CR, Binkhorst RA, Hopman MT. Body temperature responses in spinal cord injured individuals during exercise in the cold and heat. Int J Sports Med. 2006;27:599-604.

11. Price MJ. Thermoregulation during exercise in individuals with spinal cord injuries. Sports Med. 2006;36:863-79.

12. Yamasaki M, Kim KT, Choi SW, Muraki S, Shiokawa M, Kurokawa T. Characteristics of body heat balance of paraplegics during exercise in a hot environment. J Physiol Anthr Appl Hum Sci. 2001;20:227-32.

13. Hopman MT. Circulatory responses during arm exercise in individuals with paraplegia. Int J Sports Med. 1994;15:126-31.

14. Hopman MT, Oeseburg B, Binkhorst RA. Cardiovascular responses in persons with paraplegia to prolonged arm exercise and thermal stress. Med Sci Sports Exerc. 1993;25: 577-83.

15. Fitzgerald PI, Sedlock DA, Knowlton RG. Circulatory and thermal adjustments to prolonged exercise in paraplegic women. Med Sci Sports Exerc. 1990;22:629-35.

16. Zacharakis ED, Kounalakis SN, Nassis GP, Geladas ND. Cardiovascular drift in trained paraplegic and able-bodied individuals during prolonged wheelchair exercise: effect of fluid replacement. Appl Physiol Nut Metab. 2013;38:375-81.

17. Karpman VL. [The theoretical analysis of Fick's equation. On the centennial of the use of Fick's principle in physiology]. Z Kardiol. 1975;64:801-8.

18. Takagi $\mathrm{S}$, Murase $\mathrm{N}$, Kime $\mathrm{R}$, Niwayama $\mathrm{M}$, Osada $\mathrm{T}$, Katsumura T. Skeletal muscle deoxygenation abnormalities in early post-myocardial infarction. Med Sci Sports Exerc. 2014; 46:2062-9.

19. Vasiliadis AV, Zafeiridis A, Dipla K, Galanis N, Chatzidimitriou D, Kyparos A, et al. Circulating angiogenic biomolecules at rest and in response to upper-limb exercise in individuals with spinal cord injury. Spinal Cord Med. 2014;37:226-32.

20. Fukuoka Y, Nakanishi R, Ueoka H, et al. . Effects of wheelchair training on $\mathrm{VO} 2$ kinetics in the participants with spinal-cord injury. Disabil Rehabil Assist Technol. 2006;1:167-74.

21. Eriks-Hoogland I, Hilfiker R, Baumberger M, Balk S, Stucki G, Perret C. Clinical assessment of obesity in persons with spinal cord injury: validity of waist circumference, body mass index, and anthropometric index. Spinal Cord Med. 2011;34:416-22.

22. Horiuchi M, Fadel PJ, Ogoh S. Differential effect of sympathetic activation on tissue oxygenation in gastrocnemius and soleus muscles during exercise in humans. Exp Physiol. 2014;99: $348-58$.

23. Ogata H, Arimitsu T, Matsuura R, Yunoki T, Horiuchi M, Yano $\mathrm{T}$. Relationship between oxygenation in inactive biceps brachii muscle and hyperventilation during leg cycling. Physiol Res. 2007;56:57-65.

24. Ando S, Yamada Y, Kokubu M. Reaction time to peripheral visual stimuli during exercise under hypoxia. J Appl Physiol. 2010;108:1210-6.

25. Patterson MS, Chance B, Wilson BC. Time resolved reflectance and transmittance for the non-invasive measurement of tissue optical properties. Appl Opt. 1989;28:2331-6.
26. McCully KK, Hamaoka T. Near-infrared spectroscopy: what can it tell us about oxygen saturation in skeletal muscle? Exerc Sport Sci Rev. 2000;28:123-7.

27. Horiuchi M, Endo J, Dobashi S, Handa Y, Kiuchi M, Koyama K. Muscle oxygenation profiles between active and inactive muscles with nitrate supplementation under hypoxic exercise. Physiol Rep 2017;5:e13475.

28. Lafrenz AJ, Wingo JE, Gaino MS, Cureton KJ. Effect of ambient temperature on cardiovascular drift and maximal oxygen uptake. Med Sci Sports Exerc. 2008;40:1065-71.

29. Wingo JE, Lafrenz AJ, Gaino MS, Edwards GL, Cureton KJ. Cardiovascular drift is related to reduced maximal oxygen uptake during heat stress. Med Sci Sports Exerc. 2005;37:248-55.

30. Astorino TA, Bediamol N, Cotoia S, Ines K, Koeu N, Menard N, et al. Verification testing to confirm VO2max attainment in persons with spinal cord injury. J Spinal Cord Med. 2018;22:1-8.

31. Walter M, Krassioukov AV. Autonomic nervous system in paralympic athletes with spinal cord injury. Phys Med Rehabil Clin N Am. 2018;29:245-66.

32. Cariga P, Catley M, Mathias CJ, Savic G, Frankel HL, Ellaway $\mathrm{PH}$. Organization of the sympathetic skin response in spinal cord injury. J Neurol Neurosurg Psychiatry. 2002;72:356-60.

33. Muraki S, Yamasaki M, Ishii K, Kikuchi K, Seki K. Relationship between core temperature and skin blood flux in lower limbs during prolonged arm exercise in persons with spinal cord injury. Eur J Appl Physiol Occup Physiol. 1996;72:330-4.

34. Shaffrath JD, Adams WC. Effects of airflow and work load on cardiovascular drift and skin blood flow. J Appl Physiol: Res, Environ Exerc Physiol. 1984;56:1411-7.

35. Wingo JE, Cureton KJ. Body cooling attenuates the decrease in maximal oxygen uptake associated with cardiovascular drift during heat stress. Eur J Appl Physiol. 2006;98:97-104.

36. Nose H, Mack GW, Shi XR, Morimoto K, Nadel ER. Effect of saline infusion during exercise on thermal and circulatory regulations. J Appl Physiol (1985). 1990;69:609-16.

37. Nose H, Takamata A, Mack GW, Oda Y, Kawabata T, Hashimoto $\mathrm{S}$, et al. Right atrial pressure and forearm blood flow during prolonged exercise in a hot environment. Pflug Arch: Eur J Physiol. 1994;426:177-82.

38. Ekelund LG. Circulatory and respiratory adaptation during prolonged exercise of moderate intensity in the sitting position. Acta Physiol Scand. 1967;69:327-40.

39. Hopman MT, Oeseburg B, Binkhorst RA. Cardiovascular responses in paraplegic subjects during arm exercise. Eur J Appl Physiol Occup Physiol. 1992;65:73-78.

40. Hopman MT, Pistorius M, Kamerbeek IC, Binkhorst RA. Cardiac output in paraplegic subjects at high exercise intensities. Eur J Appl Physiol Occup Physiol. 1993;66:531-5.

41. Olive JL, Slade JM, Bickel CS, Dudley GA, McCully KK. Increasing blood flow before exercise in spinal cord-injured individuals does not alter muscle fatigue. J Appl Physiol. 2004;96:477-82.

42. Spungen AM, Adkins RH, Stewart CA, Wang J, Pierson RN Jr., Waters RL, et al. Factors influencing body composition in persons with spinal cord injury: a cross-sectional study. J Appl Physiol. 2003;95:2398-407.

43. Totosy de Zepetnek JO, Ditor DS, Au JS, MacDonald MJ. Impact of shear rate pattern on upper and lower limb conduit artery endothelial function in both spinal cord-injured and able-bodied men. Exp Physiol. 2015;100:1107-17.

44. Boot CR, Groothuis JT, Van Langen H, Hopman MT. Shear stress levels in paralyzed legs of spinal cord-injured individuals with and without nerve degeneration. J Appl Physiol. 2002;92:2335-40.

45. Hopman MT, Groothuis JT, Flendrie M, Gerrits KH, Houtman S. Increased vascular resistance in paralyzed legs after spinal cord injury is reversible by training. J Appl Physiol. 2002;93:1966-72. 
46. Nash MS, Montalvo BM, Applegate B. Lower extremity blood flow and responses to occlusion ischemia differ in exercisetrained and sedentary tetraplegic persons. Arch Phys Med Rehab. 1996;77:1260-5.

47. Gater DR. Weight after SCI: the good, the bad and the ugly. J Spinal Cord Med. 2017;40:138-40.

48. Rosety-Rodriguez M, Camacho A, Rosety I, Fornieles G, Rosety MA, Diaz AJ, et al. Low-grade systemic inflammation and leptin levels were improved by arm cranking exercise in adults with chronic spinal cord injury. Arch Phys Med Rehab. 2014;95: 297-302.

49. Chen Y, Henson S, Jackson AB, Richards JS. Obesity intervention in persons with spinal cord injury. Spinal Cord. 2006;44:82-91.

50. de Groot PC, Hjeltnes N, Heijboer AC, Stal W, Birkeland K. Effect of training intensity on physical capacity, lipid profile and insulin sensitivity in early rehabilitation of spinal cord injured individuals. Spinal Cord. 2003;41:673-9.

51. Hooker SP, Wells CL. Effects of low- and moderate-intensity training in spinal cord-injured persons. Med Sci Sports Exerc. 1989;21:18-22.
52. Bresnahan JJ, Farkas GJ, Clasey JL, Yates JW, Gater DR. Arm crank ergometry improves cardiovascular disease risk factors and community mobility independent of body composition in high motor complete spinal cord injury. J Spinal Cord Med. 2018; 15:1-21.

53. Nightingale TE, Walhin JP, Thompson D, Bilzon JLJ. Impact of exercise on cardiometabolic component risks in spinal cordinjured humans. Med Sci Sports Exerc. 2017;49:2469-77.

54. Nightingale TE, Metcalfe RS, Vollaard NB, Bilzon JL. Exercise guidelines to promote cardiometabolic health in spinal cord injured humans: time to raise the intensity? Arch Phys Med Rehabil. 2017;98:1693-704.

55. Van Loan MD, McCluer S, Loftin JM, Boileau RA. Comparison of physiological responses to maximal arm exercise among able-bodied, paraplegics and quadriplegics. Paraplegia. 1987;25: $397-405$.

56. Hopman MT, Dallmeijer AJ, Snoek G, van der Woude LH. The effect of training on cardiovascular responses to arm exercise in individuals with tetraplegia. Eur J Appl Physiol Occup Physiol. 1996;74:172-9. 